\title{
SOBRE LA DOCTRINA «UNWILLING OR UNABLE STATE» (¿PODRÍA EL FIN JUSTIFICAR LOS MEDIOS?)
}

\author{
María José Cervell HorTaL *
}

SUMARIO: 1. INTRODUCCIÓN.-2. USAR LA FUERZA CONTRA ESTADOS QUE NO QUIEREN O NO PUEDEN CONTROLAR A GRUPOS TERRORISTAS EN SU TERRITORIO.-2.1. Contenido de la teoría que la defiende.-2.2. Pero una cosa es exigir al Estado que reprima y prevenga el terrorismo [...].-2.3. Y otra, usar la fuerza en legítima defensa cuando no sea capaz de hacerlo.-2.3.1. La legítima defensa es posible, sí, parece, frente a actores no estatales.-2.3.2. ¿Pero es el Estado también responsable por actividades que no puede o (en particular) no quiere controlar?-3. SU APLICACIÓN AL CONFLICTO DE SIRIA.-4. UNA TEORÍA DUDOSA.-4.1. Que no es generalmente aceptada.-4.2. Y para la que podrían existir alternativas.- -5 . CONCLUSIONES.

\section{INTRODUCCIÓN}

1. El avance de la amenaza terrorista en los últimos años ha obligado a los Estados a replantearse algunos de los cimientos normativos del uso de la fuerza en Derecho internacional. A grandes males, grandes remedios, parece haber sido la reflexión subyacente para defenderse del terrorismo yihadista.

2. La posibilidad de que un Estado emplee la fuerza en territorio de otro, sin su consentimiento, por su incapacidad o falta de voluntad de frenar a grupos terroristas que desde allí atacan a otros, conocida en terminología anglosajona como la teoría unwilling or unable to act (teoría del Estado que no quiere o no puede), ha sido probablemente uno de los intentos más arriesgados. En ella se basaba Estados Unidos para, en septiembre de 2014, justificar sus ataques en territorio sirio con el fin de frenar al Estado Islámico (también conocido como Daesh). Aunque los primeros ecos de este argumento habían surgido unos años antes, parte de la doctrina (no mayoritaria, como se señalará) comenzó entonces a apoyar su propagación, y ciertos Estados (no tan

* El presente trabajo se ha desarrollado en el marco del Proyecto Der 2015-64205-R, MINECO/ FEDER (IP1: Cesáreo Gutiérrez Espada, IP2: María José Cervell Hortal). María José Cervell Hortal es Profesora Titular de Derecho Internacional Público y Relaciones Internacionales en la Universidad de Murcia (cervell@um.es). Todas las páginasweb de referencia se consultaron por última vez el 15 octubre de 2017. 
numerosos como algunos pretenden) se sintieron también tentados a recurrir a ella para justificar sus (re)acciones armadas.

3. A lo largo de los siguientes apartados se analizará el contenido y la base jurídica de la teoría, así como la posibilidad de que se esté haciendo un hueco para ella en el Derecho internacional. Se intentará, también, encontrar alternativas a la misma que permitan hacer frente al terrorismo en Estados que poco hacen para controlarlo.

\section{USAR LA FUERZA CONTRA ESTADOS QUE NO QUIEREN O NO PUEDEN CONTROLAR A GRUPOS TERRORISTAS EN SU TERRITORIO}

\subsection{Contenido de la teoría que la defiende}

4. La posibilidad de intervenir, de ser necesario incluso por la fuerza, en el territorio de otro Estado cuando este no quiera o no sea capaz de frenar la amenaza terrorista, ha sido invocada por algunos en los últimos años, sobre todo en la lucha contra el Daesh en Siria. Su argumento principal gira en torno a la idea de que todo Estado es el responsable máximo de controlar su territorio y evitar que en él se produzcan actos de terrorismo o que desde él se preparen y organicen atentados en otros Estados, de manera que, cuando no lo haga, el Estado víctima podría suplirlo en ese papel y emprender acciones directas (armadas, incluso) contra esos grupos ${ }^{1}$.

5. La teoría se ha empleado en la mayoría de casos vinculada directamente a la legítima defensa. La consolidación del terrorismo yihadista como amenaza global y la dificultad de combatirlo con los métodos clásicos han forzado a los Estados a moverse en arenas movedizas, buscando para defenderse diferentes opciones. Flexibilizar los requisitos de la legítima defensa ha sido una de las salidas más recurrentes, por ser la única (junto con la acción colectiva del Consejo de Seguridad) que permite a los Estados emplear la fuerza en el marco del Derecho, pero la teoría del Estado que no quiere o no puede pretende incluso, parece, ir más allá.

6. Cuando Estados Unidos anunciaba, en septiembre de 2014, que estaba dispuesto a atender la solicitud que Irak, al amparo de la legítima defensa (colectiva), le había formulado para acabar con el Daesh, declaró que el territorio sirio también sería su objetivo, pues de allí provenían gran parte de las acciones que ese Gobierno (el sirio) no podía o no quería impedir. Así puede

\footnotetext{
1 Las intervenciones solicitadas o consentidas por un Estado no serán objeto de análisis en este artículo, aunque sí sea conveniente, acaso, reseñar que el avance del terrorismo internacional ha favorecido que algunos las hayan permitido para contenerlo. Al respecto, Cervell Hortal, M. ${ }^{\text {a J., }} \mathrm{La}$ legítima defensa en el Derecho internacional contemporáneo (nuevos tiempos, nuevos actores, nuevos retos), Valencia, Tirant lo Blanch, 2017, pp. 34-35, y van STEENBERGHE, R., «Les interventions militaires étrangères récentes contre le terrorisme international. Première partie: fondements juridiques", AFDI, vol. LXI, 2015, pp. 145-198, esp. pp. 148-161.
} 
constatarse en la carta enviada al secretario general y al presidente del Consejo de Seguridad, el 23 de septiembre de 2014:

"Iraq has made clear that it is facing a serious threat of continuing attacks from the Islamic State in Iraq and the Levant (ISIL) coming out of safe havens in Syria. [...]. States must be able to defend themselves, in accordance with the inherent right of individual and collective self-defence, as reflected in Article 51 of the Charter of the United Nations, when, as is the case here, the government of the State where the threat is located is unwilling or unable to prevent the use of its territory for such attacks $»^{2}$ (redonda añadida).

¿Qué base tenía la teoría que Estados Unidos alegaba? No aparece en tratado alguno, ni la jurisprudencia la ha acogido, con lo que, de momento y como las páginas siguientes reafirmarán, no puede calificarse sino de propuesta, defendida por algunos Estados y un sector doctrinal que busca revestir de legalidad acciones armadas que de acuerdo con el estricto Derecho internacional en vigor no está claro que la tengan.

7. En realidad, el argumento no es tan novedoso, y aunque han sido varios los partidarios de la fórmula, acaso la referencia obligada entre los iusinternacionalistas sea la del artículo publicado por la Profesora Ashley Deeks en $2012^{3}$, que lleva a cabo un detallado repaso de las ocasiones en las que, a su entender, se ha empleado la teoría, sus funciones y su metodología ${ }^{4}$. El artículo originó no pocas críticas que diferentes publicaciones, tanto en revistas como en red, se encargaron de recoger ${ }^{5}$. Daniel Bethlehem, ese mismo año, esta vez en el American Journal of International Law, proponía 16 principios aplicables a la legítima defensa frente a actores no

\footnotetext{
2 Doc. S/2014/695, 23 de septiembre de 2014.

3 DEEKs, A., «Unwilling or unable: toward a normative framework for extraterritorial self-defense», Virginia Journal of International Law, vol. 52, 2012, núm. 3, pp. 482-550.

${ }_{4}$ Se incluyen cinco elementos que deberían considerarse antes de emprender una acción armada de estas características: 1) priorizar el consentimiento o la cooperación con el Estado territorial antes de recurrir unilateralmente a la fuerza; 2) solicitar al Estado territorial que se enfrente a la amenaza y darle tiempo adecuado para responder; 3) evaluar el control y capacidad del Estado territorial en esa región; 4) evaluar los medios propuestos por el Estado territorial para eliminar la amenaza, y 5) evaluar las interacciones previas que se hayan hecho con ese Estado (DEEKs, A., op. cit., nota 3, pp. 490 y 519 y ss.).

5 Véase por ejemplo, Ahmed, D. I., «Defending weak States against the unwilling or unable doctrine of self-defense», Journal of International Law and International Relations, vol. 9, 2013, pp. 1-13 (p. 4: los académicos que han reflexionado sobre la doctrina, afirma, lo han hecho apartándose de la realidad de que los Estados víctimas a menudo suelen ser poderosos y los que son atacados en su nombre, Estados débiles que no siempre pueden responder con una legítima defensa). También CoRTEN, O., "The unwilling or unable test: has it been, and could it be, accepted?», Leiden Journal of International Law, vol. 29, 2016, pp. 777-799, esp. pp. 779-780, y TLADI, D., «The non consenting innocent State: the problems with Bethlehem's Principle 12», AJIL, vol. 107, 2013, pp. 570-576. Especialmente crítico se ha mostrado Kevin J. Heller en el blog Opinio Juris (http://opiniojuris.org/); véanse las entradas «The unwilling or unable standard for self-defense», de 17 de septiembre de 2011; "Ashley Deeks problematic defense of the Unwilling or Unable test», de 15 de diciembre de 2011, y "The absence of practice supporting the Unwilling or Unable Test», de 17 de febrero de 2015. Otros autores, aunque no tan abiertamente críticos, son también cautos a la hora de aceptar que estemos ante una teoría consolidada (HAKIмI, M., "Defensive force against non-State actors: the state of play», International Legal Studies, vol. 91, 2015, pp. 1-31, esp. p. 31).
} 
estatales y, aunque el número 10 era contrario a las intervenciones no consentidas en terceros Estados ${ }^{6}$, los dos siguientes recogían excepciones al respecto: cuando el Estado conspire con el actor no estatal o no sea contrario a sus acciones (principio 11) y cuando sea incapaz de frenarlas (principio 12).

8. En sus orígenes más remotos, la teoría estuvo también directamente vinculada al fenómeno terrorista. Fue, en particular, la inactividad del Gobierno ugandés uno de los argumentos esgrimidos por Israel, en 1976, para penetrar en su territorio y liberar a los pasajeros (israelíes) de un avión secuestrado por terroristas palestinos ${ }^{7}$.

Después de esa fecha, hubo más ocasiones en las que los Estados usaron puntualmente la fuerza contra grupos armados o terroristas en territorio de otros a los que se acusaba de apoyar o cobijar movimientos de esta naturaleza. Estados Unidos ha sido, como se reafirmará en las páginas siguientes, el principal adalid de la teoría, que ha vinculado además precisamente con la figura de la legítima defensa, en un intento de revestirla de mayor legalidad. De hecho, ya en 1984, un memorando del Presidente Ronald Reagan declaraba que los Estados víctimas de terrorismo tienen derecho a actuar en legítima defensa y que el uso de la fuerza no consensuado era justificable si el Estado que cobijaba a los terroristas era «unable or unwilling to take effective action» ${ }^{8}$. Esa ha sido también la postura mantenida tras la irrupción de $\mathrm{Al}$ Qaeda en 2001 y, después (2014), del Daesh.

9. Otros Estados han recurrido de manera puntual a argumentos similares para justificar acciones armadas en territorio de otros: Turquía en 1996 en sus incursiones en el norte de Irak contra terroristas kurdos ${ }^{9}$; Rusia en 2002 al atacar bases chechenas en territorio de Georgia ${ }^{10}$; Israel en sus incursiones en el Líbano contra Hezbolá en $2006{ }^{11}$; Colombia al invadir en 2008 territorio de Ecuador persiguiendo rebeldes de las FARC ${ }^{12}$; o Kenia en sus incursiones

${ }^{6}$ Bethlehem, D., "Notes and comments. Principles relevant to the scope of a State's right of selfdefense against an imminent or actual armed attack by nonstate actors», AJIL, vol. 106, 2012, pp. 1-8, esp. p. 7 .

7 Doc. S/PV.1939, de 9 de julio de 1976. El representante israelí denunció la falta de seguridad del aeropuerto (párr. 70) y la colaboración de las autoridades ugandesas con los terroristas, defendiendo su actuación en el derecho inherente de defensa propia (párr. 101).

8 Memorandum for Edwin Meese III, 15 de agosto de 1984 (apartado «The use of force against terrorist acts»). El archivo, confidencial durante un tiempo, puede hoy consultarse en http://www.washingtondecoded.com/files/nsdd.pdf. Al respecto, REINOLD, T., «State weakness, irregular warfare and the right of self-defense post-9/11», AJIL, vol. 105, 2011, núm. 2, pp. 244-286, esp. p. 251.

9 Doc. S/1996/479, de 2 de julio de 1996. Sobre la cuestión, RuYs, T., "Quo vadit jus ad bellum? A legal analysis of Turkey's military operations against the PKK in Northern Iraq", Melbourne Journal of International Law, vol. 9, 2008, núm. 2, pp. 334-364.

10 Doc. S/2002/1012, de 12 de septiembre de 2002 (Carta del Representante de Rusia) y la respuesta de Georgia (Doc. S/2002/1035, de 16 de septiembre).

11 Israel alegó, de hecho, que respondía «a un acto de guerra» y fueron no pocos los Estados que la apoyaron (Doc. S/PV. 5489, de 14 de julio de 2006, p. 6).

12 Colombia alegó expresamente legítima defensa (véase Doc. S/2008/146), aunque Ecuador y Venezuela hablaron de agresión para calificar las actuaciones colombianas. La OEA condenó la actuación [Doc. CP/Res 930 (1631/08), de 5 de marzo de 2008], pero Estados Unidos la apoyó. 
de 2011 en territorio somalí13. Y, por supuesto, otros encontraron en la guerra contra el Daesh la ocasión perfecta para, ante la falta de éxito del gobierno sirio de acabar con el grupo terrorista, invocar la posibilidad de actuar contra él (véase infra párrs. 26 y ss.).

10. La teoría encontró eco también en determinadas instituciones. En 2005, la Chatham House británica publicaba los Principios de Derecho internacional sobre el uso de la fuerza por los Estados en legitima defensa ${ }^{14}$, que partiendo (principio 6) de la aceptación de la legítima defensa para ataques de actores no estatales, concretaba que si ese derecho se ejercía en el territorio de otro Estado «debe ser evidente que ese Estado no puede o no quiere lidiar con los propios actores no estatales». Se afirma, asimismo, que si bien el Estado no es responsable de los actos de los terroristas, sí lo es por no tomar las medidas necesarias "para prevenir el uso de su territorio como una base para los ataques de otros Estados».

11. Dos puntualizaciones son necesarias respecto de los casos de la práctica mencionados: en primer lugar, todos ellos tienen como telón de fondo el terrorismo y se aprecia cierta dejadez de los Gobiernos implicados en reprimirlo; en segundo lugar, salvo en la lucha contra el Daesh, en la mayoría de supuestos se ha tratado de incursiones puntuales, a veces con un uso mínimo de la fuerza o en zonas totalmente fuera de control del Estado.

Pero la teoría del Estado que no quiere o no puede pretende, a la luz de lo que afirman sus defensores en los últimos tiempos, ir más allá, y permitir, de ser necesario, el uso de la fuerza contra grupos terroristas de manera continuada, incluso, en el territorio de Estados que hayan intentado, pero no conseguido, reprimir esos actos; podrá verse con más claridad en los desarrollos sucesivos. Las voces que pedían, desde 2001 y ante el crecimiento continuado de la amenaza terrorista, una legítima defensa más amplia y más flexible para poder reaccionar de manera adecuada, han visto en esta teoría una manera más de apuntalar sus argumentos.

\subsection{Pero una cosa es exigir al Estado que reprima y prevenga el terrorismo [...]}

12. Es norma consolidada en Derecho internacional que todo Estado tiene la obligación de no permitir que se emplee su territorio para fines contrarios a los derechos de otros Estados ${ }^{15}$. Pero una cosa es la obligación de

13 LuBELl, N., Extraterritorial use of force against non state actors, Oxford, Oxford University Press, 2010, pp. 31 y ss., y TRAPP, K. N., «Back to basics: necessity, proportionality, and the right of self-defence against non-state terrorist actors", ICLQ, vol. 56, 2007, núm. 1, pp. 141-156.

14 Entre cuyos autores puede encontrarse a internacionalistas británicos de renombre (Doc. NP ILP WP 05/01, p. 6, disponible en https://www.chathamhouse.org/publications/papers/view/108106 y en ICLQ, vol. 55, 2006, núm. 4, pp. 963-972). La intención perseguida al formular esos principios era, como se afirma desde la propia institución, «aclarar las normas del Derecho internacional que regulan el uso de la fuerza por los Estados en legítima defensa».

15 En sede arbitral, resulta obligada la referencia al asunto Trail Smelter (Sentencia arbitral de 11 de marzo de 1941), entre Estados Unidos y Canadá (RIAA, vol. III, pp. 1905-1982, esp. p. 1963). Como 
frenar el terrorismo y otra, como pretende la teoría del Estado que no quiere o no puede, llevarlo a sus últimas consecuencias y permitir, incluso, usar la fuerza en su territorio y sin su consentimiento.

Los Estados, en efecto, están obligados a reprimir y prevenir las acciones de grupos terroristas. El desarrollo de esta obligación se ha visto impulsado por la emergencia del fenómeno en los últimos años y su origen es doble, pues emana tanto de tratados internacionales como de resoluciones del Consejo de Seguridad. Son, en efecto, numerosos los convenios que de manera expresa contemplan la prevención, sanción y castigo del terrorismo ${ }^{16}$, pero al ser de naturaleza sectorial (centrados en problemas concretos como acciones llevadas a cabo en aeronaves, ataques contra personas internacionalmente protegidas, toma de rehenes, atentados terroristas con bombas, financiación del terrorismo...) solo ofrecen soluciones parciales, a lo que se une el hecho de que no todos cuentan con la misma participación (en cuanto al número de Estados parte).

Por otro lado, la actividad del Consejo de Seguridad en lo que a terrorismo se refiere ha sido especialmente intensa desde 2001, estableciendo muchas de sus resoluciones obligaciones concretas para castigar, extraditar, perseguir o prevenir las acciones de grupos terroristas en territorio de los Estados ${ }^{17}$; algunas de las cuales, por lo demás, han planteado para un sector doctrinal dudas sobre si el alcance y generalidad de su contenido serían conformes con las competencias del Consejo. La irrupción del Daesh en 2014 desataba una nueva fiebre sancionadora del Consejo ${ }^{18}$.

afirmara la CIJ en el asunto del estrecho de Corfú, se trata de un principio general bien reconocido (Sentencia de 9 de abril de 1949, ICJ Reports 1949, p. 4, p. 22). La referencia al principio surgiría también en el asunto sobre el personal diplomático y consultar en Teherán (Sentencia de 24 de mayo de 1980, ICJ Reports 1980, p. 3, pp. 32-33). Véase PISsILlo MAZZESCHI, R., "The due diligence rule and the nature of International Responsibility of States», GYIL, vol. 35, 1993, pp. 9-51.

1619 de alcance universal (un listado de ellos en http://www.un.org/en/counterterrorism/legal-instruments.shtml). Sobre esos tratados, ad ex., SALINAS DE Frías, A. M., "Lucha contra el terrorismo internacional: no solo del uso de la fuerza pueden vivir los Estados», REDI, vol. 68, 2016, núm. 2, pp. 229-252.

17 La Resolución 1368 (2001), de 12 de septiembre, instaba a los Estados a colaborar para «someter a la acción de la justicia a los autores, organizadores y patrocinadores» de esos ataques, recalcando además que «los responsables de prestar asistencia, apoyo o abrigo a los autores, organizadores y patrocinadores de estos actos» deberían rendir cuentas. Pero es sin duda la Resolución 1373 (2001), de 28 de septiembre, la que, en virtud del Capítulo VII, compromete realmente a los Estados en la lucha contra el terrorismo, obligándoles ya a una larga lista de acciones incluidas en el párr. 2. Años más tarde, la Resolución 2133 (2014), de 27 de enero, reafirmaba todas las obligaciones impuestas por la Resolución 1373. Sobre medidas adoptadas por el Consejo contra el terrorismo, ALCAIDE FERNÁNDEZ, J., «La guerra contra el terrorismo: ¿una OPA hostil al derecho de la comunidad internacional?», REDI, vol. 53, 2001, núms. 1 y 2, pp. 289-302, esp. pp. 298-301; Blanc Altemir, A., «La respuesta de la Organización de las Naciones Unidas al terrorismo internacional», en GuTiérREZ EsPADA, C. (dir.) y CERVELL Hortal, M. ${ }^{a}$ J. (coord.), Derecho Internacional, Alianza de Civilizaciones y terrorismo global, Murcia, Diego Marín Librero Editor, 2011, pp. 49-90, esp. pp. 73-89, y DíAz BARRADo, C. M., «El marco jurídico internacional de la lucha contra el terrorismo», en Lucha contra el terrorismo y Derecho Internacional, Grupo de Trabajo núm. 6/04, Cuadernos de Estrategia, vol. 133, 2006, Instituto Español de Estudios Estratégicos, pp. 51-77, esp. pp. 63-68.

18 Principalmente, la Resolución 2178 (2014) sobre combatientes terroristas extranjeros, la Resolución 2199 (2015), sobre medidas de prohibición de comercio y la Resolución 2253 (2015) para 
13. Un Estado que, en definitiva, incumpliera alguna de estas obligaciones (por ejemplo, que no desarrollara la legislación adecuada para reprimir acciones terroristas o no acatara alguna de las disposiciones de los convenios en los que fuera parte) cometería un hecho ilícito internacional contra el que podrían adoptarse las medidas pertinentes pero, ¿y si las acciones terroristas que la inacción del Estado permite son de tal calibre que pueden equipararse a un uso de la fuerza e, incluso, a un ataque armado? ¿Sería posible entonces, recurrir a un uso defensivo de la fuerza en ese Estado pese a que no existiera una vinculación directa del grupo terrorista con él? Lo iremos viendo en las páginas que siguen.

\subsection{Y otra, usar la fuerza en legítima defensa cuando no sea capaz de hacerlo}

14. El art. 2.4 prohíbe el uso o la amenaza de la fuerza en las relaciones internacionales contra la integridad territorial o la independencia política de cualquier Estado. La Resolución 2625 (XXV), de 24 de octubre de 1970, que recoge la Declaración sobre Principios de Derecho Internacional declara, además, expresamente:

«todo Estado tiene el deber de abstenerse de organizar, instigar, ayudar o participar en actos de guerra civil o en actos de terrorismo en otro Estado, o de consentir actividades organizadas dentro de su territorio encaminadas a la comisión de dichos actos, cuando los actos a que se hace referencia en el presente párrafo impliquen el recurrir a la amenaza o al uso de la fuerza» (cursiva añadida).

Y unos años después, la Resolución 42/22 de la Asamblea General, de 18 de noviembre de 1987, y su Declaración sobre el mejoramiento de la eficacia del principio de la abstención de la amenaza o la utilización de la fuerza en las relaciones internacionales reiteraba esa prohibición en su apartado 1.6.

15. Un Estado que organice, instigue, ayude, participe o consienta actos de terrorismo que impliquen un uso de la fuerza viola la prohibición del art. 2.4 de la Carta de las Naciones Unidas. Comete, por tanto, un hecho ilícito internacional ${ }^{19} \mathrm{y}$ abre así la puerta a otras respuestas de Estados que entendieran que esas acciones eran alentadas de alguna manera por el Estado

\footnotetext{
ampliar al Daesh las sanciones que hasta esa fecha se aplicaban a Al Qaeda. También la Resolución 2249 (que exhortaba a los Estados a adoptar todas las medidas necesarias para prevenir y reprimir los actos terroristas en territorio bajo el control de Daesh en Irak y Siria) reiteraba en su Preámbulo la Resolución 1373. Sobre las acciones del Consejo de Seguridad respecto del Daesh, Cervell HorTaL, M. ${ }^{a}$ J., «El Derecho Internacional: ¿una herramienta eficaz en la lucha contra el Daesh?», en CERVELL Hortal, M. ${ }^{a}$ J. (dir.), Estado Islámico, Naciones Unidas, Derecho Internacional y Unión Europea, Granada, Comares, 2017, pp. 42-57, y GutiéRrez EsPADA, C., "Choque de civilizaciones (el autoproclamado Estado Islámico). Respuesta de la Comunidad Internacional. ¿Una Alianza de Civilizaciones contra el Estado Islámico", en Soroeta Liceras, J. (dir.), Anuario de los Cursos de Derechos Humanos de Donostia-San Sebastián, vol. XVI, Thomson Reuters Aranzadi, 2017, pp. 111-214, esp. pp. 122 y ss. y 178 y ss.

19 Como confirmara la CIJ en el asunto sobre actividades militares y paramilitares en y contra Nicaragua, ICJ Reports 1986, p. 14, párr. 195 de la sentencia.
} 
desde donde actúa el grupo terrorista ${ }^{20}$. Y si esos actos fueran de la entidad suficiente como para ser considerados un ataque armado, podría incluso invocarse la legítima defensa prevista en el art. 51 de la Carta. Pero la teoría del Estado que no quiere o no puede cruza esa línea: la legítima defensa puede activarse, no solo contra y en el territorio del Estado que organice, instigue, ayude o participe en esos actos de terrorismo, sino también contra grupos terroristas en el territorio del Estado que permanezca inactivo o que, pese a haber adoptado medidas para refrenarlos, no haya tenido éxito. Es decir, en el caso de un Estado pasivo o incapaz y si las acciones terroristas fueran de la entidad y gravedad suficientes como para ser consideradas un ataque armado, otros podrían invocar la legítima defensa y ejercerla, no contra el Estado mismo (por decirlo así), pero sí en su territorio y sin su consentimiento.

La teoría plantea problemas respecto de dos cuestiones desde el punto de vista jurídico: de un lado, parte del convencimiento de que la legítima defensa es también posible frente a acciones de actores no estatales y, de otro, rompe en cierto modo con las reglas tradicionales de la atribución de responsabilidad, al no ser necesaria la existencia de un vínculo claro entre grupo terrorista y Estado desde el que actúa, para poder llevar a cabo en el territorio de ese Estado y aun sin su consentimiento un uso de la fuerza contra los terroristas.

\subsubsection{La legítima defensa es posible, sí, parece, frente a actores no estatales}

16. La teoría que aboga por usar la fuerza contra el Estado que no quiere o no puede frenar las acciones de grupos terroristas en su territorio supone llevar al extremo, como se ha señalado, la concepción actual de la legítima defensa, al tiempo que da por sentadas algunas premisas previas aún no consolidadas de manera generalizada en Derecho internacional. En concreto, parte de la idea de una legítima defensa ejercida directamente contra actores no estatales (por más que se lleve a cabo en el territorio de un Estado tercero).

17. Ha sido esta cuestión, junto con la de inminencia, uno los aspectos más debatidos de la figura de la legítima defensa en los últimos años ${ }^{21}$. ¿Es posible alegarla también cuando sean entidades distintas a los Estados quienes lleven a cabo ataques armados? No lo prohíbe expresamente el art. 51,

20 Véase GutiÉRrez EsPADA, C., «La responsabilidad internacional del Estado por el uso de la fuerza armada (la conformación del hecho ilícito internacional)», Cursos de Derecho Internacional y Relaciones Internacionales de Vitoria-Gasteiz, 1989, Bilbao, Universidad del País Vasco, 1990, pp. 185-310, esp. pp. 292-293.

${ }^{21}$ Véase IDI, 10. ${ }^{\text {a }}$ Resolution, 27 de octubre de 2007, 10ème Commission, Problèmes actuels du recours à la force en droit International, IDI, Sesión de Santiago, 2007, párr. 3; ILA, Report on Aggression and the Use of Force, International Law Association, Johannesburg Conference, 2016, pp. 10-11. Entre la doctrina, puede citarse ARMSTRONG, A., «The past and future of the claim of preemptive self-defense», $A J I L$, vol. 100, 2006, núm. 3, pp. 525-550; RoscINI, M., «Threats of armed force and contemporary International Law», NILR, vol. 54, 2007, pp. 229-277, y SzABÓ, K. T., Anticipatory action in self-defence. Essence and limits under International Law, La Haya, TMC Asser Press, 2011. 
pero en cuanto se concibió como una excepción al art. 2.4 de la Carta, que prohíbe el uso de la fuerza a los Estados, pudiera pensarse que solo a estos afecta. Así se pensaba, en efecto, una vez redactada, pero la realidad terminaría probando que también actores no estatales podían recurrir a la fuerza, a veces incluso en iguales o muy parecidas condiciones que los Estados. La Resolución 3314 (XXIX), de 14 de diciembre de 1974, empieza a tenerlo en cuenta, aunque fuera a los efectos de atribuir a un Estado los actos armados físicamente cometidos por grupos armados que no formaban parte de su sistema orgánico institucional [art. 3.g): un acto de agresión también puede ser cometido (físicamente) por bandas armadas, grupos irregulares o mercenarios que un Estado envía o que participa sustancialmente en los mismos]. Esta posibilidad, perfectamente comprensible en una sociedad cambiante, empieza a ser insuficiente cuando se trata de grupos armados que no son dirigidos por ningún Estado ni enviados por él, pero que cometen actos armados de gravedad equiparable al ataque armado, lo que se manifiesta de manera especial desde el 11 de septiembre de 2001 con el terrorismo yihadista. Los criterios de imputación al Estado no resultan claros en algunos casos (Al Qaeda en Afganistán) y en otros ni siquiera existen (Daesh), pero estos grupos actúan desde territorios de Estados que no son capaces de gestionarlos.

18. Dos resoluciones ya mencionadas del Consejo de Seguridad (Resoluciones 1368 y 1373, ambas de 2001) fueron las que, tras el ataque de Estados Unidos contra Afganistán, sin suponer un beneplácito significativamente claro (la referencia a la legítima defensa como respuesta a los atentados del 11-S se hace en el preámbulo de la Resolución 1373), demostraron una actitud más comprensiva hacia la legítima defensa contra actores no estatales, algo que también se advierte tanto en la doctrina ${ }^{22}$ como en la práctica. Estados

22 Son muchos quienes la defienden. Entre otros, Bethlehem, D., «Self-defence against an imminent or actual armed attack by nonstate actors», AJIL, vol. 106, 2012, núm. 4, pp. 769-777; BERMEJO GARcía, R., «El Derecho Internacional frente al terrorismo: ¿nuevas perspectivas tras los atentados del 11 de septiembre?», $A D I$, vol. 17, 2001, pp. 5-24, esp. pp. 23 y 24; id., "La legítima defensa y el Derecho Internacional en los albores del siglo XXI", Los nuevos escenarios internacionales y europeos del Derecho y la Seguridad, Madrid, Colección Escuela Diplomática, 2003, núm. 7, pp. 127-141, esp. p. 138, y «La paz y seguridad internacionales en el sistema de Naciones Unidas: algunas reflexiones en torno al uso de la fuerza y evolución en su septuagésimo aniversario», en Pons Rafols, X. (dir.), Las Naciones Unidas desde España, 70 Aniversario de las Naciones Unidas, 60 Aniversario del ingreso de España en las Naciones Unidas, Barcelona, ANUE, 2015, pp. 169-192; CASSESE, A., "Article 51 », en Cot, J. P., Pellet, W. y Forteau, M. (dirs.), La Charte des Nations Unies, Commentaire article par article, París, Económica, 3. a ed., 2005, pp. 1329-1360, esp. p. 1352 (si son ataques masivos y de gravedad considerable, matiza); DinsteIn, Y., War, aggression and self-defence, Cambridge, Cambridge University Press, $4 .^{\text {a }}$ ed., 2005, pp. 204-208; FrANCK, T. M., "Terrorism and the right of self-defense», AJIL, vol. 95, 2001, pp. 839-843, esp. p. 840; GutiérREz EsPADA, C., «Sobre la prohibición del uso de la fuerza armada en los últimos sesenta años (1945-2015)», en Pons Rafols, X. (dir.), Las Naciones Unidas desde España, 70 Aniversario de las Naciones Unidas, 60 Aniversario del ingreso de España en las Naciones Unidas, Barcelona, ANUE, 2015, pp. 125-150, esp. pp. 138-139; KRETZMER, D., "The inherent right to self-defence and proportionality in Jus ad bellum», EJIL, vol. 24, 2013, núm. 1, pp. 235-282, esp. pp. 246-250; Murphy, S., "Self-Defense and the Israeli Wall Advisory Opinion: an ipse dixit from the ICJ?», AJIL, vol. 99, 2005, núm. 1, pp. 62-76; id., "Terrorism and the concept of armed attack in article 51 of the UN Charter», Harvard Journal of International Law, vol. 43, 2002, núm. 1, pp. 42-51, esp. p. 51, y Randelzhofer, A., "Article 51», en Simma, B., Mosler, H., Randelzhofer, A., Tomuschat, C. y Wolfrum, R. (eds.), The Charter of the United Nations. A commentary, vol. I, 2. ${ }^{a}$ ed., Oxford, Oxford 
Unidos aboga claramente por su aceptación ${ }^{23}$, secundado por otros (Israel, Rusia, Turquía ${ }^{24}, \ldots$ ), cuya lista se ampliaba tras la irrupción del terrorismo del Daesh (véase infra párr. 19).

También otros indicadores revelan que puede que algo esté cambiando respecto de esa nueva concepción en la legítima defensa: si el IDI (Instituto de Derecho Internacional) en 2007 aceptaba aún tímidamente la posibilidad en su resolución de Santiago de Chile ${ }^{25}$, menos reparos encontraba nueve años después la ILA (International Law Association), que ya reconocía «un creciente reconocimiento, incluida la práctica estatal, de que hay determinadas circunstancias en las que un Estado podría ejercer el derecho de legítima defensa contra actores no estatales que operen fuera de sus fronteras ${ }^{26}$. Reflexiones aún más recientes sobre el uso de la fuerza y la legítima defensa lo confirman (Manual de Tallín sobre Ciberguerra de 2013, revisado en 2017) ${ }^{27}$.

19. El Daesh ha influido, qué duda cabe, respecto de la posible consolidación de la norma que permitiría la legítima defensa contra actores no estatales. Las reacciones de los Estados parecen afirmar que, al menos, ya hay un grupo de Estados (los más de 60 que conforman la Coalición Internacional que contra él lucha) convencidos, pues no en vano esa legítima defensa es la base para sus actuaciones en Irak y en Siria. Alguno de ellos ha llegado incluso a alegar la legítima defensa de carácter individual (ya no colectiva en ayuda de Irak) cuando el Daesh lo ha puesto directamente en su punto de mira. Lo hacía, por ejemplo, Egipto tras la decapitación pública y televisada en una playa de Libia de varios de sus nacionales (febrero de 2015), Rusia después del derribo de un avión sobre la península del Sinaí con varios compatriotas a bordo (octubre de 2015), Francia tras los atentados de París de 13 de noviembre de 2015 o Turquía para defender su frontera con Siria de la amenaza terrorista. Incluso los Estados miembros de la Unión Europea pa-

University Press, 2002, pp. 788-806, esp. p. 802, y TAMS, C. J., "The use of force against terrorists», EJIL, vol. 20, 2009, núm. 2, pp. 359-397.

${ }_{23}$ Estrategias de Seguridad Nacional estadounidenses de 2002 (p. 5), 2006 (p. 8), 2010 (p. 20) y 2015 (p. 7), disponibles en http://nssarchive.us/. También el Informe sobre los parámetros jurídicos del empleo de la fuerza por Estados Unidos de diciembre de 2016 declara que «el derecho inmanente de legítima defensa no se restringe a amenazas que emanen de Estados» (Report on the legal and policy frameworks guiding the United States' use of military force and related national security operations, diciembre de 2016, https://www.whitehouse.gov/sites/whitehouse.gov/files/documents/Legal_Policy_Report. $p d f$, p. 9).

${ }^{24}$ Véase supra párr. 9.

25 Da por sentada una interpretación más amplia del art. 51, al aceptar que este, «tal y como ha sido completado por el Derecho internacional consuetudinario» pueda aplicarse en caso de ataque armado de un "actor no estatal», concretando que es factible cuando uno de esos ataques se lance «desde el espacio fuera de la jurisdicción de cualquier Estado» (Resolución de 27 de octubre de 2007, op. cit., nota 21 , párr. 10).

26 Sesión de Johannesburgo (ILA, Report on Aggression and the Use of Force, op . cit., nota 21, p. 11).

27 Elaborado a instancias del Centro de Excelencia de ciberdefensa cooperativa de la OTAN y cuyas reflexiones y conclusiones, aunque con el ciberespacio como marco de referencia, son aplicables al uso de la fuerza en general: Tallinn Manual on the International Law applicable to cyberwarfare, Cambridge, Cambridge University Press, 2013, pp. 58-59, párr. 16, norma 13 y Tallinn Manual 2.0 on the International Law applicable to cyberoperations, Cambridge, Cambridge University Press, 2017, p. 345, párr. 18, norma 18. 
recen partidarios de abrazar la nueva tendencia ¿no es, acaso, lo que puede deducirse del apoyo prestado a Francia después de que esta invocase la cláusula de defensa mutua del art. 42.7 del TUE tras los atentados de París? ${ }^{28}$. ¿Ha sido el Daesh solo una excepción o hay futuro para la legítima defensa frente a actores no estatales? Tal y como la sociedad internacional evoluciona y cómo se comportan sus actores, quizá no sea descabellado pensar que esa opción ha llegado para quedarse.

20. No ha comulgado aún la Corte Internacional de Justicia (CIJ), sin embargo, con esta tendencia, y en los últimos asuntos en los que tuvo que pronunciarse sobre la cuestión se mantuvo fiel a una concepción tradicional de la legítima defensa ${ }^{29}$, si bien es cierto que ya son bastantes los años transcurridos desde entonces y diferentes las circunstancias de fondo. ¿Se mostraría más comprensiva si tuviera que hacerlo hoy? Sería deseable, sí, que aclarara la cuestión y, probablemente, que reconociera asimismo lo que ya no pocos ven con buenos ojos.

\subsection{2. ¿ ¿Pero es el Estado también responsable por actividades que no puede o (en particular) no quiere controlar?}

21. Las intervenciones y el uso de la fuerza en el territorio de Estados desde los que operan grupos terroristas y que no han podido o sabido atajarlos cuestionan algunos de los planteamientos tradicionales de la atribución de responsabilidad. La teoría implica (aunque sea de algún modo) responsabilizar al Estado por lo que esos grupos terroristas hacen en o desde su territorio (ad ex. planificar atentados terroristas en otro Estado) y por no defender la activación de las acciones pertinentes (uso de la fuerza en legítima defensa). Y por más que se alegue que ese uso de la fuerza no es contra el Estado en sí, sino que simplemente se desarrolla en su territorio, las consecuencias prácticas no varían significativamente (se emplea la fuerza y se viola la integridad territorial del Estado). Aunque esta posibilidad haya sido sobre todo una respuesta necesaria a una amenaza de gran calibre (el terrorismo yihadista y, sobre todo, el del Daesh), acogerla en su generalidad sería seguramente peligroso.

${ }^{28}$ Véase Outcome of the Council Meeting 3426th, Council Meeting Foreign Affairs, Bruselas, 16 y 17 de noviembre de 2015, Doc. 14120/15 (OR. en) PRESSE 69 PR CO 61. Sobre el mecanismo del artículo, GoutTEFARDE, F., «L'invocation de l'article 42.7 TUE ou la solidarité militaire europeenne a l'épreuve de la guerre contre le terrorisme», RGDIP, vol. 120, 2016, núm. 1, pp. 51-67, y GonZÁLEZ ALONSo, L. N., «¿Daños jurídicos colaterales? La invocación del artículo 42.7 del Tratado de la Unión Europea y la lucha contra el terrorismo internacional», REEI, vol. 32, 2016, pp. 1-23.

${ }_{29}$ Opinión Consultiva en el asunto sobre la construcción de un muro en territorio de Palestina (ICJ Reports 2004, p. 136): Israel no convenció a la Corte respecto de la existencia de un derecho de legítima defensa (párr. 139 de la Opinión, que contó, todo sea dicho, con las críticas de tres de sus jueces, Kooijmans, Higgins y Buergenthal; párrs. 35, 33 y 6 de sus Opiniones, respectivamente). Tampoco va más lejos en el asunto sobre actividades armadas en territorio del Congo (2005) (ICJ Reports 2005, p. 168; párr. 148 de la sentencia, también cuestionado por los Jueces Simma en los párrs. 28 y 29 de su Opinión y Kooijmans en el párr. 12 de la suya). 
Es cierto que, de momento, su aceptación ha sido limitada (véase infra párrs. 26 y ss.), pero ¿quién asegura que en el futuro no se pretenderá su aplicación a nuevos casos vinculados a otros grupos terroristas o, incluso, frente a otras amenazas? La posibilidad puede parecer aún hoy remota, o no... En septiembre de 2017, la convocatoria de un referéndum en el Kurdistán, un territorio al norte de Irak que no controla de facto, para determinar la posible independencia de la región movía al Gobierno de Turquía a declararse dispuesto a una intervención militar en la zona si el proceso de libre determinación proseguía, "ante el temor de que las votaciones fomenten las ideas secesionistas kurdas en Turquía», entendiendo que se trataba de "una amenaza para la seguridad nacional del país» ${ }^{30}$.

22. Conforme a las reglas generales que rigen la responsabilidad internacional de un Estado por la comisión de un hecho ilícito, recogidas por la Comisión de Derecho Internacional (CDI) en su Proyecto de $2001^{31}$, y consideradas en gran medida Derecho consuetudinario, un Estado sería responsable de actos cometidos por particulares (grupos o bandas armadas), siempre y cuando actúen por sus instrucciones o bajo su dirección y control (art. 8). De esta forma, para exigir responsabilidades a un Estado y, en su caso, llevar a cabo las acciones pertinentes, sería necesaria la existencia de unos vínculos con el grupo terrorista que, como sabido es, ha dado lugar a discusiones acerca de si bastaría con un control efectivo (de acuerdo con la CIJ en su sentencia sobre actividades militares y paramilitares en y contra Nicaragua, de 27 de junio de 1986) ${ }^{32}$ o general (según el Tribunal Penal para la ex Yugoslavia en el asunto Tadic) ${ }^{33}$, decantándose finalmente tanto la CIJ como la CDI por la primera $^{34}$.

23. Bastaría, pues, determinar quién ejerce el control de esos grupos y atribuir la responsabilidad pertinente. Y, sin embargo, tras los atentados contra Estados Unidos en 2001 comienza a abrirse paso la posibilidad de imputar cierta responsabilidad (y, en su caso, actuar en legítima defensa) al Estado

30 Diario $A B C, 24$ de septiembre de 2017 y The New York Times, 25 de septiembre de 2017.

31 Proyecto de artículos sobre la responsabilidad del Estado por hechos internacionalmente ilícitos, Informe de la Comisión a la Asamblea General sobre la labor realizada en su 53. ${ }^{\circ}$ periodo de sesiones (23 de abril a 1 de junio de 2001 y 2 de julio a 10 de agosto de 2001), Doc. A/CN.4/SER.A/2001/

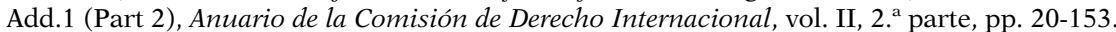

32 ICJ Reports 1986, p. 14, párr. 86 de la sentencia.

33 Prosecutor v. Dusko Tadic, Appeals Chamber, caso núm. IT-94-1-1, Judgement, 15 de julio de 1999, párrs. 90-145. Lo defendió también en otros asuntos: Trial Chamber, Prosecutor v. Ivica Rajuc A/k/a Victor Andric, Review of the indictment pursuant to rule 61 of the Rules of Procedure and Evidence, caso núm. IT-95-12, 13 de septiembre de 1996, párrs. 9-32, 24 y ss.; Trial Chamber, Prosecutor v. Tihomir Blaskic, Sentencia de 3 de marzo de 2000, caso núm. IT-95-14, párrs. 73-123, y Prosecutor v. Zlatko Aleksovski, Sentencia de 24 de marzo de 2000, caso núm. IT-95-14/1. También el Tribunal Europeo de Derechos Humanos (asunto Loizidou c. Turquía, aplicación núm. 15318/89, Sentencia de 18 de diciembre de 1996, párrs. 49-57).

${ }^{34} \mathrm{La}$ CIJ en el asunto sobre la aplicación de la Convención para la prevención y represión del crimen de genocidio (Bosnia-Herzegovina c. Serbia y Montenegro), ICJ Reports 2007, p. 43, párrs. 377-415 y 425 y ss. de la sentencia y la CDI en Proyecto sobre Reponsabilidad internacional de los Estados (véanse los comentarios al art. 8 del Proyecto, op. cit., nota 31, pp. 49-51; véase también CRAWFORD, J., State responsibility. The general part, Cambridge, Cambridge University Press, 2014, p. 156). 
que no dirige o controla al grupo terrorista, pero cuya presencia sí tolera en su territorio. Ese fue, de hecho, el argumento empleado por el Gobierno estadounidense en la intervención en Afganistán en $2001^{35}$, Estado en donde Al Qaeda actuaba sin muchas trabas gubernamentales y que, como se indicó, el Consejo de Seguridad indirectamente también pareció aceptar (Resoluciones 1368 y 1373 de 2001).

El terrorismo comenzaba, por tanto, a relajar las reglas del juego, pero la CIJ seguía firme en sus argumentos: cuando en 2005 se pronunció, en el asunto de las actividades armadas en territorio de la República Democrática del Congo, sobre la pretensión ugandesa de que el Gobierno congoleño había incumplido su deber de vigilancia para impedir que grupos irregulares atacaran su territorio, consideró que ese deber no supone una obligación de resultado, sino que dependía de las circunstancias y, sobre todo, de las condiciones y medios que tuviera el Estado en cuestión para hacerles frente, precisando además que no podía concluirse que la ausencia de acción del Gobierno congoleño fuera equivalente a tolerar o consentir sus actividades ${ }^{36}$. Dos jueces defendieron, sin embargo, que las actividades de bandas armadas podrían ser consideradas un ataque armado incluso si no hubieran sido enviadas o controladas por Estado alguno ${ }^{37}$.

24. El que la mera tolerancia de grupos irregulares pueda traducirse, si llevan a cabo un ataque armado, en legítima defensa contra ellos pero en el territorio de un Estado y sin su consentimiento, es, creo, y por más que algunos Estados lo hayan aplicado, aún discutible a la luz del Derecho internacional $^{38}$. Y pretender, yendo más allá de la mera tolerancia, que incluso el hecho de no poder hacerles frente sea argumento suficiente para el empleo de la fuerza resulta, si cabe, aún más arriesgado. Otras serán las responsabilidades que puedan surgir para ese Estado, pero permitir que contra su voluntad se use la fuerza armada en su territorio violenta, a mi entender, la situación actual de la cuestión. Es cierto que el Daesh ha sido en gran medida el culpable de forzar aún más el argumento (reaccionar contra al Estado que no quiere o no puede) pero, como he señalado, acaso no deba ser considerado más que una solución extrema para un caso concreto que no debiera generalizarse.

25. El Estado tiene obligaciones respecto del terrorismo, pero son obligaciones de comportamiento, no de resultado, con lo que un Estado que ha mostrado una diligencia debida en la lucha contra el terrorismo no debiera

35 Véase la Declaración de 18 de septiembre de su Presidente George W. Bush (https://georgewbushwhitehouse.archives.gov/news/releases/2001/09/20010918-10.html).

36 Véanse párrs. 276, 301 y 303 de la sentencia. A este respecto, GutiérREz EsPADA, C. y CERVELL

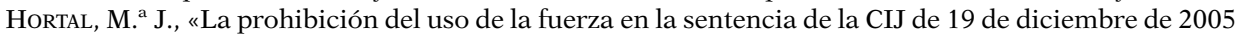
(asunto sobre las actividades armadas en el territorio del Congo, República Democrática del Congo c. Uganda)», REDI, vol. 58, 2006, núm. 1, pp. 239-256, esp. p. 25, y OKowA, P. N., "Case concerning armed activities on the territory of the Congo (Democratic Republic of the Congo v. Uganda)», ICLQ, vol. 55, 2006, núm. 3, pp. 742-753, esp. p. 749.

37 Parr. 27 de la opinión individual del Juez Kooijmans y párrs. 8 y 12 de la del Juez Simma.

38 Conten, O., Le droit contre la guerre. La interdiction du recours à la force en droit international contemporain, París, Pédone, 2014, p. 718. 
considerarse que incumple sus obligaciones ni tampoco, desde luego, tener que soportar una respuesta armada de otros en violación de su soberanía territorial por no hacerlo. De otro modo, estaríamos admitiendo en la práctica algo que ni el art. 51 ni la Resolución 3314 (1974) contemplan: que el concepto de ataque armado puede incluir conductas de grupos armados ajenos a él (al Estado) que, pese a haberlo intentado, no ha podido reprimir ${ }^{39}$.

Cosa distinta sería, claro está, la otra opción que la teoría proclama: que un Estado no quiera contener las actividades del grupo terrorista, pues no parece ya en este caso darse excusa razonable que justifique su pasividad.

Es, con todo, difícil cuestión, puesto que si así planteada resulta lógica, la realidad (en particular la impuesta por el Daesh, sin líneas rojas en cuanto a los actos terroristas se refiere y con el objetivo declarado de persistir hasta alcanzar la meta del Califato universal) ha desbordado todos los razonamientos posibles: actuar como se ha hecho puede haber sido la única manera de hacerle frente. Las dudas que, pese a todo, la intervención suscitaba, pesaron seguramente en la decisión de los Estados que han actuado contra esa organización terrorista de dejar claro que no lo hacían contra Siria, sino en territorio de Siria, y que sus objetivos se seleccionaban de manera cuidadosa, intentando limitarlos solo a bases militares o campos de entrenamiento de la organización (se aceptará en todo caso que, cuando un grupo terrorista adquiere tal poder que es capaz de, incluso, controlar ciudades y a su población, la elección cuidadosa de objetivos no siempre será fácil...).

\section{SU APLICACIÓN AL CONFLICTO DE SIRIA}

26. Es en Siria donde se desencadena el flujo doctrinal sobre esta doctrina que se ha llamado la del «Estado que no quiere o no puede». La guerra contra el Daesh que se empezó a librar allí (además de en Irak) a partir de septiembre de 2014, ha sacado con fuerza a relucir la posibilidad de intervenir en un Estado (Siria) que no lograba poner coto al terrorismo transacional, global, de organizaciones yihadistas radicales. La situación era, en este caso, especialmente complicada, pues aunque la sociedad internacional ya había tenido que enfrentarse a los actos de Al Qaeda en los últimos años, los métodos empleados por el Daesh para sembrar el terror, su proclamación como

39 Pissillo-MAZZECHI, R., op. cit., nota 15, pp. 41-42: "A State's failure to act diligently to comply with its positive obligations, such as the duty to prevent terrorism is not an act of aggression, but only a breach of the autonomous rule of customary law which binds the State to prevent, in its territory, the organization of acts of force against foreign States». Poco partidario también de exigir una obligación de resultado a los Estados es Crawford, J., The International Law Commission's Articles on State responsability, Cambridge, Cambridge University Press, 2002: las obligaciones de prevención «are usually construed as best efforts obligations requiring States to take all reasonable or necessary measures to prevent a given event from occurring, but without warranting that the event will not occur» (p. 140) y ProulX, V.-J., "Babysitting terrorists: should States be strictly liable for failing to prevent transborder attacks», Berkeley Journal of International Law, vol. 23, 2005, núm. 3, pp. 615-668. También en esa línea, CoRTEN, O., op. cit., nota 5 , p. 795. 
Califato con el objetivo, estratégicamente publicitado por las estrategias del que llegó a ser un proto-Estado, de expandirse e imponer su particular versión del Islam y su conquista del territorio de otros Estados lo hacía, si cabe, más peligroso.

Estados Unidos (supra párr. 6) atendía la petición de ayuda de Irak, invocando la legítima defensa (pese a que en su carta, el Gobierno iraquí no lo había hecho formalmente) y anunciando que también desplegaría sus acciones en Siria, por la incapacidad de su Gobierno en hacer frente al Daesh. Las acciones en suelo sirio se llevaban a cabo, además, bajo el paraguas de la Coalición Global contra el Daesh ${ }^{40}$, liderada por Estados Unidos.

27. El argumento de usar la fuerza contra un Estado que ha dejado patente su incapacidad o poca voluntad para luchar contra el terrorismo encontraba, en definitiva, en Siria, su máxima expresión, pero Estados Unidos no ha cesado desde entonces en insistir en su legalidad. En abril de 2016, ante miembros de la American Society of International Law, Brian Egan (exasesor jurídico del Departamento de Estado estadounidense) declaraba:

"The U.S.'s use of force in self-defense (including defense of Iraq) is necessary because Syria is "unable" to adequately deal with the threat from ISIL» ${ }^{41}$.

28. Por su parte, el Informe sobre los parámetros políticos y jurídicos de Estados Unidos sobre el uso de la fuerza, que describía las pautas seguidas por la Administración Obama a la hora de usar la fuerza más allá de sus fronteras, de diciembre de 2016, la abrazaba sin $\operatorname{rodeos}^{42}$ y ya no en relación a la necesidad de actuar contra el Daesh, sino de manera general.

29. Cuando Estados Unidos anunció su intención de actuar en Irak y Siria, algunos Estados compartieron el argumento de la legítima defensa (recordemos, ejercida contra un actor no estatal), pero no todos comulgaron con que la razón fuera la incapacidad del Gobierno sirio. La legítima defensa se invocaba, sí, no solo por el Gobierno estadounidense, sino también por Canadá, Australia, Turquía, Francia, Alemania, Dinamarca, Países Bajos y Bélgica $^{43}$, pero solo los tres primeros mencionaban expresamente la doctrina del Estado que no quiere o no puede para justificarla. Reino Unido se incorporaba a la lista en noviembre de $2015^{44} \mathrm{y}$, aunque en su momento lo hizo solo

40 http://theglobalcoalition.org/en/partners/.

41 El vídeo de su conferencia puede consultarse en https://www.youtube.com/watch?v=4ol8Fz-ShaY (Keynoteaddress: Brian Egan).

${ }^{42}$ Op. cit., nota 23, pp. 9 y 10, https://www.whitehouse.gov/sites/whitehouse.gov/files/documents/Legal_Policy_Report.pdf: en algunos supuestos, se afirma en él, «el Derecho internacional no exige a un Estado que obtenga el consentimiento del Estado en cuyo territorio se usará la fuerza contra un grupo armado no estatal», porque los Estados deben defenderse si «el gobierno del Estado del que emana la amenaza es incapaz o renuente de prevenir el uso de su territorio por un actor no estatales para esos ataques».

43 Docs. S/2015/221 (Canadá), S/2014/695 (Estados Unidos), S/2015/693 (Australia) y S/2015/563 (Turquía).

44 Lo hacía su entonces Primer Ministro, David Cameron, ante el Parlamento, justificando las acciones británicas porque «el régimen de Assad no quiere y/o no puede tomar acciones necesarias para prevenir los continuos ataques del ISIS en Irak» (véase la sesión ante la Cámara de los Comunes de 
respecto de la guerra contra el Daesh, en enero de 2017, el fiscal general del Estado británico, en un discurso en el Instituto Internacional de Estudios Estratégicos, bajo el título «El Derecho actual de la legítima defensa», declaraba que para derrotar al terrorismo no basta con desarrollar una serie de normas que lo persigan, sobre todo «cuando los ataques se planean desde fuera de nuestro territorio y el Estado que los acoge no puede o no quiere actuar» ${ }^{45}$.

30. Otros, cierto es, pese a no acogerla expresamente, tampoco la criticaron $^{46}$. Alemania y Bélgica, aunque no tan claramente, dejaron entrever en sus declaraciones que el Estado sirio no tenía el control efectivo de su territorio, que era de donde provenían los ataques ${ }^{47}$.

31. El representante sirio denunció ante el Consejo de Seguridad que las conductas de la Coalición no respetaban su integridad territorial, que eran fruto de una lectura "distorsionada» del art. 51 y que su país había hecho no pocos esfuerzos para combatir el terrorismo islamista ${ }^{48}$. Pero demoró el hacerlo prácticamente un año desde que se iniciaran las incursiones en su territorio (mientras que en ocasiones anteriores de injerencias de Estados terceros sus protestas fueron prácticamente inmediatas ${ }^{49}$. Esa tardanza, así como ciertas declaraciones de dirigentes sirios que dejaban entrever que algunos de los primeros ataques fueron notificados a su Gobierno, ha llevado a algunos a afirmar que hubo un consentimiento, al menos implícito, a los ataques anteriores a septiembre de $2015^{50}$.

26 de noviembre de 2015, Column 1467, en https://publications.parliament.uk/pa/cm201516/cmhansrd/ cm151126/debtext/151126-0001.htm).

$45 \mathrm{El}$ discurso puede consultarse en https://www.gov.uk/government/speeches/attorney-generalsspeech-at-the-international-institute-for-strategic-studies. Afirma, además, que un número de Estados ha confirmado esta posibilidad, si bien es cierto que toma como fuente para ello el artículo de CHACHKO, E. y DeEks, A. («Who is on board with “Unwilling or Unable”?»), publicado por Lawfare, 10 de octubre de 2016 (https://www.lawfareblog.com/who-board-unwilling-or-unable) en el que el listado (en algunos casos discutible) de Estados que han aceptado sin duda alguna la teoría incluye solo a 10 (véase infra nota 53).

${ }^{46}$ De hecho, respecto de Francia, la declaración enviada al Consejo de Seguridad cuando este Estado comenzó sus ataques sobre Siria, deja abiertas muchas cuestiones respecto de su fundamentación. Tras recordar la petición de ayuda hecha por Irak en legítima defensa colectiva en septiembre de 2014, declara que, «de acuerdo el artículo 51 de la Carta de las Naciones Unidas, Francia ha tomado acciones relativa a la participación de aviones militares en respuesta a los ataques llevados a cabo por el Daesh desde el territorio de la República Árabe Siria». No se alude a la incapacidad o renuencia directamente del Estado sirio para paralizar los ataques, pero sí parece aceptarse la justificación dada por Estados Unidos (véase Identical letters dated 8 September 2015 from the Permanent Representative of France to the United Nations addressed to the Secretary-General and the President of the Security Council, Doc. S/2015/745, de 9 de septiembre de 2015).

47 Docs. S/2015/221, de 31 de marzo; S/2015/693, de 9 de septiembre; S/2015/745, de 8 de septiembre; S/2015/946, de 10 de diciembre; S/2016/34, de 13 de enero, y S/2016/523, de 9 de junio, respectivamente.

48 Doc. S/2015/719, de 21 de septiembre de 2015, y Doc. A/70/385-S/2015/727, de 22 de septiembre de 2015 .

49 Contra Israel (Doc. S/2014/885, 15 de diciembre de 2014) o Turquía (Doc. S/2015/132, de 23 de febrero), por citar dos ejemplos.

$50 \mathrm{Al}$ respecto, BANNELIER-CHRISTAKIs, K., «Military interventions against ISIL in Iraq, Syria and Libya, and the legal basis of consent», Leiden Journal of International Law, vol. 29, 2016, pp. 743-775, esp. pp. 770-771; CORTEN, O. y VERDEBOUT, A., «Les interventions militaires récentes en territoire étran- 
32. No ha habido, por otro lado, bien por razones políticas, bien porque se consideraba que el fin justificaba en este caso los medios, condena oficial del secretario general de las Naciones Unidas que, en una declaración del 23 de septiembre de 2014, quitaba hierro al asunto, matizando que pese a no haber existido petición previa, sí se había informado al Gobierno sirio de que los ataques tendrían lugar ${ }^{51}$. Las palabras del secretario general, por lo demás, pudieran plantearnos otra cuestión: ¿desde cuándo es la (mera) notificación una justificación válida para atacar en un Estado soberano?

33. Ha sido, en suma, en Siria, la legítima defensa el argumento aceptado para intervenir, por los Estados, por la Coalición contra el Daesh e incluso por la Unión Europea, cuyos miembros respondían a la invocación por Francia de la cláusula de defensa mutua del art. 42.7 del TUE tras los atentados de París de noviembre de 2015 (véase supra párr. 19). No hubo, sin embargo, una clara aceptación de llevar la legítima defensa al extremo ni se afirmó expresamente que se actuaba porque el Estado era incapaz de frenar la amenaza terrorista; ¿cuáles fueron las razones?

Sin duda, resulta aún, esta, una teoría con sombras y no acabada de asentar del todo en la legalidad internacional. Hubo Estados que optaron entonces por una concepción más amplia de la legítima defensa, sin duda, porque la guerra de Siria y el avance del Daesh han generado una situación excepcional que, como tal, necesitaba también de respuestas excepcionales. De ahí que la Resolución 2249 (2015) del Consejo de Seguridad, que exhortaba a los Estados miembros a «adoptar todas las medidas necesarias» (párr. 5), por más que su lenguaje fuera conscientemente ambiguo y no invocara el Capítulo VII de la Carta, se consideró tan necesaria: ¿había que dotar de una aparente cobertura a acciones estatales cuya justificación jurídica no estaba clara y permitir así que los Estados limpiaran sus conciencias? ${ }^{52}$.

\section{UNA TEORÍA DUDOSA}

\subsection{Que no es generalmente aceptada}

34. La teoría del Estado que «no quiere o no puede» ha logrado suscitar cierto interés como una posible salida frente a casos en los que, como Siria

ger: vers une remise en cause du Jus contra bellum?», AFDI, vol. LX, 2014, pp. 135-169, esp. p. 153, y VAN STEEnBerghe, R., op. cit., nota 1, p. 160.

51 "I am aware that today's strikes were not carried out at the direct request of the Syrian Government, but I note that the Government was informed beforehand. I also note that the strikes took place in areas no longer under the effective control of that Government", Remarks at the Climate Summit press conference (including comments on Syria) Secretary-General Ban Ki-moon, 23 de septiembre de 2014, United Nations News Center, https://www.un.org/sg/en/content/sg/speeches/2014-09-23/remarks-climatesummit-press-conference-including-comments-syria.

52 Véase ad ex, además de la doctrina citada en la nota 18, Pozo SERrano, P., «El uso de la fuerza contra el Estado Islámico en Irak y Siria: problemas de fundamentación jurídica», AEDI, vol. 32, 2016, pp. 141-188, esp. pp. 179 y ss. 
y el Daesh, resultaba difícil luchar conforme a la legalidad vigente contra un grupo terrorista que operaba desde un Estado concreto. Su empuje resultó favorecido por una corriente doctrinal dispuesta a defenderla y por un grupo de Estados que la incorporaban a sus parámetros de actuación.

Ha sido, sin embargo, o eso me parece, más el ruido que las nueces. Frente a lo que sus (no tan numerosos) defensores declaran, no puede hablarse de una clara opinio iuris como la chispa capaz de inflamar el estallido de una norma consetudinaria en formación. Estados de cierto peso (Estados Unidos, Reino Unido, Canadá, Australia y Turquía) la han apoyado, pero podrían hacerse dos matices. En primer lugar, todos menos Estados Unidos y Reino Unido lo han hecho solo en el contexto de la guerra contra el Daesh, es decir, en una situación sin precedentes similares y, en segundo lugar, el número de quienes la defienden sigue siendo minoritario ${ }^{53}$. Ya en 2006, la Liga de Estados Árabes, a la que se unieron China, Irán, Cuba y Venezuela, rechazaron la teoría cuando Israel la planteó como argumento para sus ataques contra Hezbollá en Líbano ${ }^{54}$. Y no son pocos Estados los que forman parte de la Coalición contra el Daesh que no la han acogido de manera expresa, como ya he señalado.

35. No existe, por otro lado, apoyo jurisprudencial alegable. En el asunto de las actividades armadas en territorio del Congo, recuérdese, la CIJ no fue partidaria de admitir que la ausencia de acción del gobierno congoleño fuera equivalente a tolerar o consentir las actividades de los grupos que actuaban en su territorio ${ }^{55}$. Y si bien es cierto que ha llovido mucho desde entonces y, de llegar el caso, la Corte podría ahora mostrarse más comprensiva respecto de este tipo de planteamientos, resulta con todo, en mi opinión, difícilmente concebible que aceptara una teoría como la del Estado que no quiere o no puede actuar contra grupos terroristas.

36. Instituciones de peso y renombre en la esfera internacional (más allá de los mencionados en su momento) tampoco lo han tenido claro. El IDI, en su sesión de Chile (2007), no consideró siquiera oportuno plantear la cuestión de qué ocurriría en el caso de una intervención en el territorio de un Estado incapaz de frenar la amenaza terrorista. La ILA en 2016 sí admitía ya, como sabemos, la legítima defensa contra actores son estatales, pero mostraba su preocupación por la posibilidad de ir más lejos, de manera que matizó que cuando estos grupos operen dentro de las fronteras de un Estado, «el Estado víctima puede tener un derecho de legítima defensa contra el grupo

\footnotetext{
53 ChachKo, E. y DeEKs, E. (op. cit., nota 45), hacen un listado de Estados (basándose en declaraciones oficiales de sus Gobiernos) organizado en cuatro categorías: I, apoyo explícito; II, apoyo implícito; III, casos ambiguos y IV, objetores. Dentro de la categoría I, ya se apuntó, solo aparecen diez Estados, lo que refuerza la idea de que la existencia de una opinio iuris es más que discutible.

${ }^{54}$ Véanse los Docs. S/PV.5493 y S/PV.5493 (reanudación) de 21 de julio de 2006. Israel había justificado su ataque en legítima defensa en la inacción del Gobierno libanés (UN Doc. A/60/937-S/2006/515, de 12 de julio: «La ineptitud y pasividad del Gobierno del Líbano han permitido que se genere esta situación de no ejercicio de la jurisdicción en su propio territorio»).

55 Véase nota 36.
} 
armado, pero no contra el Estado", con lo que debería afinar bien el ataque para que en modo alguno afectara a las instituciones gubernamentales y/o a los nacionales de ese Estado. Que tamaña precisión sea posible es algo que no puede garantizarse, y la ILA afirmaba que de no ser así, se violaría, en efecto, el art. 2.4 de la Carta ${ }^{56}$.

Fue, probablemente, también esta teoría la que movió a un grupo de profesores de Derecho internacional de la Universidad Libre de Bruselas a poner en circulación una Declaración contra la invocación abusiva de la legítima defensa contra el terrorismo, afirmando expresamente que «el simple hecho de que un Estado sea, a pesar de sus esfuerzos, incapaz de dar término a los actos terroristas en su territorio, no puede ser suficiente para justificar el bombardeo del mismo sin su consentimiento ${ }^{57}$. Pero... ¿y si no quisiera? Ni el Manifiesto ni la ILA lo aclararon, ¿quizá porque este era un caso distinto a aquel que no puede?

37. Son, pues, numerosos los problemas que plantea la teoría del Estado que no quiere o no puede. No solo porque la mayoría de Estados haya optado por no pronunciarse expresamente al respecto, sino porque presenta además puntos débiles desde el punto de vista jurídico. Permitiría emplear la fuerza evaluando parámetros de política interna y de seguridad de los Estados (si es o no capaz de controlar esos grupos y sus actividades) y obligaría incluso a quienes hubieran mostrado diligencia en la lucha contra el terrorismo a afrontar graves consecuencias (sufrir intervenciones de terceros y el uso de la fuerza en su territorio), algo que, hoy por hoy, no encuentra apoyo en el Derecho internacional en vigor ${ }^{58}$. Falla, además, al obviar el hecho de que, en realidad, en la mayoría de casos, los Estados hacen todo cuanto les resulta posible para librar a su territorio de la lacra del terrorismo (son ellos los primeros interesados) y que incluso en ciertos casos no dudan en pedir ayuda a terceros Estados a tal fin. Pero, incluso si diéramos por sentado que un Estado es incapaz de hacerlo..., ¿cómo valorar esa incapacidad? ${ }^{59}$. Es, en suma, quizá pronto para asumir y aceptar, en lo que se refiere a acciones de control del terrorismo, la conversión automática de una obligación de conducta de un Estado en una obligación de resultado ${ }^{60}$.

56 Op. cit., nota 21, pp. 12 y 13. Esas medidas tendrían que ser «proporcionadas y limitarse a aquellas estrictamente necesarias en el contexto de legítima defensa contra el actor no estatal» (p. 13).

57 En http://cdi.ulb.ac.be/contre-invocation-abusive-de-legitime-defense-faire-face-def-terrorisme/.

58 Tsagourias, N., "Self-Defence against non-State actors: the interaction between self defence as a primary rule and self defence as a secondary rule», Leiden Journal of International Law, vol. 29, 2016, núm. 3, pp. 801-822, esp. p. 812.

59 Es, en efecto, difícil determinar el concepto de diligencia debida. La CIJ en el asunto sobre la prevención y castigo del crimen de genocidio afirmó que depende de varios parámetros, aplicables o no según las circunstancias de cada caso (ICJ Reports 2007, p. 43, párr. 430 de la sentencia). A conclusión similar llegaba el grupo de trabajo sobre la cuestión (diligencia debida) de la ILA (ILA Study Group on Due Diligence in International Law Second Report, julio de 2016, p. 47, disponible en http://www. ila-hq.org/).

${ }_{60}$ O. Corten va incluso más lejos, afirmando que con la teoría el art. 2.4 (y la Resolución 2625) pasarían de ser obligaciones de conducta a obligaciones de resultado (CORTEN, O., op. cit., nota 5, p. 792). 
En definitiva, hay argumentos que militan en contra de la aceptación de esta construcción teórica, que en todo caso parece hecha a medida de una situación tan particular como la de Siria y el Daesh ${ }^{61}$, en la que la dificultad de colaborar con el régimen sirio forzó otro tipo de respuestas. Generalizarla para situaciones futuras resulta, entonces, injustificado.

\subsection{Y para la que podrían existir alternativas}

38. ¿Hubiera sido posible alcanzar los mismos objetivos (contener la amenaza) en el caso de la guerra contra el Daesh en Siria con otros argumentos? Tres alternativas podrían, a priori, barajarse.

39. Primera. Como ha afirmado un sector doctrinal ${ }^{62}$, la teoría unablel unwilling no tiene en realidad una existencia autónoma, sino que podría considerarse la reformulación del criterio de necesidad que, junto a la inmediatez y la proporcionalidad, debe guiar toda decisión de actuar en legítima defen$\mathrm{sa}^{63}$ y que exige que esa respuesta (armada) sea el único medio que el Estado que ha sufrido el ataque tiene a su alcance ${ }^{64}$. Ahora bien, la rigidez y exigencia conforme a los cuales se concibió el criterio hacen difícil aplicarlo en la práctica, de manera que hasta la propia CIJ ha mostrado cierta relajación en cuanto a su interpretación cuando ha tenido que lidiar con él ${ }^{65}$. Debe enten-

${ }^{61}$ Hasta lo más críticos lo han reconocido. Afirma la ILA lo siguiente: «The military operations on Syrian territory against the so-called Islamic State have, in particular, demonstrated the readiness of a number of states to invoke Article 51 in the context of operations against a non-state actor» (p. 11), mientras que el Manifiesto de la Universidad belga declara: «Sin oponernos por principio al uso de la fuerza contra los grupos terroristas — particularmente en el actual contexto de la lucha contra Daeshnosotros, profesores e investigadores en Derecho internacional, estimamos que dicha invocación creciente del derecho de legítima defensa es objetable». Por otro lado, un tanto aventurada me parece aún la afirmación de que aunque no se pueda hablar de la teoría de la incapacidad o renuencia como una norma consuetudinaria, sí que lo sucedido en Siria puede calificarse de catalizador que ha alimentado el desarrollo de dicha teoría (FLASCH, O., "The exercise of self-defence against ISIL in Syria: new insights on the extraterritorial use of force against non-state actors», Journal on the use of force and International Law, vol. 3, 2016, núm. 1, pp. 37-69, esp. p. 64).

62 VAN SteEnberghe, R., op. cit., nota 1, pp. 192-197.

63 Recuérdese que no son parámetros incluidos en la letra de la Carta sino elementos de naturaleza consuetudinaria cuyo origen data de 1837, fecha del asunto Caroline (http://avalon.law.yale.edu/19th century/br-1842d.asp). Véase JenNings, R., "The Caroline and McLeod cases», AJIL, vol. 32, 1938, pp. 82-99, y SofaER, A. D., "On the necessity of pre-emption», EJIL, vol. 14, 2003, núm. 2, pp. 209-226, esp. pp. 214-220.

${ }_{64}$ Véase Adición al $8 .^{\circ}$ informe sobre la responsabilidad de los Estados, por el Sr. Roberto Ago [El hecho internacionalmente ilícito del Estado como fuente de responsabilidad internacional (conclusión), Doc. A/CN.4/318/'Add.5 a 7, Anuario de la CDI, 1980, vol. II, 1. a parte, pp. 15-74, esp. p. 72, párr. 120]. También CoRTEN, O., "La nécessité et le Jus ad Bellum», La nécessité en Droit International. Colloque de Grenoble, Société Française pour le Droit International, París, Pédone, 2007, pp. 127-150.

${ }_{65}$ En el asunto Nicaragua (1986), la Corte evalúa la necesidad, no en el sentido de sopesar todas las opciones pacíficas antes de pasar a la solución militar, sino más bien en el de considerar que esas medidas eran realmente «necesarias» (convenientes, adecuadas) cuando se adoptaron para responder a una acción que ya había desplegado sus efectos (op. cit., nota 19, párr. 237). En el asunto de las plataformas petroliferas (Sentencia de 12 de diciembre de 2003, ICJ Reports 2003, p. 161) rechaza la legítima defensa alegada por Estados Unidos por no considerarla necesaria al haberse dirigido contra determinados objetivos que la CIJ no consideró adecuados (la destrucción de las plataformas) (párr. 76), argumento 
derse por tanto la necesidad en el sentido, no tanto de ser la única alternativa, sino de que sean esas medidas las más adecuadas o convenientes para repeler el ataque armado previo ${ }^{66}$, como en su día defendiera también el Relator de la CDI, Roberto Ago ${ }^{67}$. Aplicada a la amenaza terrorista, la respuesta armada no sería más que una defensa (frente a acciones de actores no estatales, eso sí, con lo que parte de la aceptación de la posibilidad) que se activa porque otras posibilidades son imposibles ante la gravedad de la situación. Sería necesario, en todo caso, que el Estado víctima intentara que el Estado territorial adoptara antes todas las acciones posibles para frenar al actor no estatal; de no ser así, estaría colocando al Estado que sufre los ataques (ahora sí), en un callejón sin salida que podría justificar la necesidad de actuar en legítima defensa.

40. Segunda. Relajar, dentro de unos límites precisos, la prohibición del uso de la fuerza y, en particular, permitir la aplicación de ciertas causas de exclusión de la ilicitud de manera más flexible (para que la ilegalidad del uso de la fuerza desapareciera en determinadas circunstancias), evitaría tener que recurrir a soluciones como la teoría discutida. Valga un ejemplo: el estado de necesidad como causa de exclusión de ilicitud se contempla en el art. 25 del Proyecto de la CDI sobre la responsabilidad de los Estados en el caso de que se pretenda salvar un interés esencial de un peligro grave e inminente, siempre y cuando sea este el único medio de atajarlo y el peligro (amenaza terrorista) fuera el único medio de contrarrestarlo. Pero la figura se configuró como una excepción, sometida por tanto a limitaciones estrictas para prevenir cualquier posible abuso ${ }^{68}$, con lo que no debería invocarse con alegría.

El Proyecto impide, de hecho, su invocación en dos casos: cuando resulte gravemente afectado un interés esencial de otro Estado [art. 25.1.b)] y cuando la obligación que se pretende incumplir dimane de una norma imperativa de Derecho internacional (art. 26) ${ }^{69}$, lo que directamente descarta que un

que volvió a repetir en el asunto del Congo (2005) al entender que las medidas adoptadas en legítima defensa deben suponer, para respetar el criterio de necesidad, una ventaja militar claramente justificada (op. cit., nota 29, párr. 147). Partidarios de una interpretación más flexible, CoRTEN, O., op. cit., nota 38, pp. 775-777, y GARDAM, J., Necessity, proportionality and the use of force by States, Cambridge, Cambridge University Press, 2004, pp. 149 y 153.

${ }^{66}$ Esa interpretación ha sido también defendida por la Comisión nombrada para el conflicto de Georgia (Independent International Fact-Finding Mission on the conflict of Georgia: Report, vol. II, 2009, p. 248, http://www.mpil.de/en/pub/publications/archive/independent_international_fact.cfm) o por los expertos que han elaborado el Manual de Tallín sobre la ciberguerra, que dedica no pocas páginas a la legítima defensa en general (Tallinn Manual 2.0, op. cit., nota 27, pp. 348-349, norma 72). También es la opción preferida en los Principios Chatham (op. cit., nota 14, p. 7).

${ }^{67}$ Op. cit., nota 64, párr. 119.

${ }^{68}$ Op. cit., nota 31, p. 85.

69 Son estos, además, requisitos de carácter consuetudinario, como la propia CIJ declaraba en el asunto Gabcíkovo-Nagymaros (Sentencia de 25 de septiembre de 1997, ICJ Reports 1997, p. 7, párr. 51). No es el momento de entrar en un análisis exhaustivo de la figura, sobre la que puede consultarse: Cassella, S., La nécessité en Droit international, Leiden-Boston, Martinus Nijhoff, 2011 (en particular, pp. 60 y ss.); GutiérRez EsPADA, C., El estado de necesidad y el uso de la fuerza, Madrid, Tecnos, 1987; id., El hecho ilícito internacional, Madrid, Dykinson, 2005, pp. 149 y ss.; id., «El estado de necesidad cabalga de nuevo", REDI, vol. 56, 2004, núm. 2, pp. 669-704. 
Estado pretenda borrar la ilegalidad de una acción armada alegando estado de necesidad. No siempre estuvo, empero, tan clara la cuestión durante el proceso de redacción del Proyecto: el Relator Roberto Ago ya dejó en su día entrever (1980) que, aunque no era posible alegar el estado de necesidad en casos de agresión contra otros Estados, acaso no pudiera decirse lo mismo (al menos, no con tanta rotundidad), si el uso de la fuerza fuera más bien de carácter limitado $^{70}$. De hecho, mencionaba expresamente como ejemplos la necesidad de paralizar las amenazas de fuerzas o grupos hostiles de extenderse a su territorio y en incursiones en el territorio de un Estado extranjero para impedir la acción de bandas o grupos armados cuando el Estado en el que se encuentran no pueda controlarlas ${ }^{71}$. Más allá de lo delicado del concepto (estado de necesidad) y de la imposibilidad de abordar aquí y ahora todas sus aristas, ¿tan descabellado sería volver a debatir la posibilidad?

41. Tercera. Siempre quedará al jurista internacional la posibilidad de conjurar al Consejo de Seguridad, una vez más y siempre y cuando a estas alturas aún le queden fuerzas para ello, y confiar en que cumpla de una vez con sus funciones ante amenazas graves como el terrorismo; a fin de cuentas (lo recordaba entre líneas en el párr. 5 supra de este Estudio) él es el principal responsable del mantenimiento de la paz y seguridad internacionales.

Probablemente, como ya se ha apuntado, la Resolución 2249 (2015) con la que en cierta medida respaldó las actuaciones de la Coalición contra el Daesh en Siria fue una manera de afrontar el problema, pero su ambiguo contenido y abstracto lenguaje (en un intento de contentar a todos sus miembros permanentes y evitar el veto), deslució sus buenas intenciones. ¿Habrá que conformarse con resoluciones como esta en ocasiones futuras?

\section{CONCLUSIONES}

La posibilidad de usar la fuerza contra Estados que no quieren o no pueden controlar las acciones de grupos terroristas dentro de su territorio ha irrumpido en la escena internacional en un intento de amparar actuaciones cuya legalidad internacional era dudosa. El Daesh y los ataques contra territorio sirio han alimentado aún más esta tendencia como única salida posible para cortar las alas a ese grupo terrorista.

Es, sin embargo, una teoría que excede los límites de la legalidad, no solo porque tergiversa la concepción actual de la legítima defensa, sino también porque, al justificar el empleo de la fuerza contra un Estado por no ser capaz de controlar a grupos terroristas en su territorio, termina a la postre haciéndolo responsable de acciones de grupos terroristas que, sí, es incapaz de controlar, pero con los que no existe ninguna vinculación formal. Resulta

${ }^{70}$ Adición al octavo informe sobre la responsabilidad..., op. cit., nota 64, p. 47, párrs. 65-66, y p. 41, párr. 55 in fine. Véase Gutiérrez EsPADA, C., op. cit., nota 20, pp. 283-295; id., "El estado de necesidad cabalga...", op. cit., nota 69, pp. 682-691.

71 Op. cit. nota 64, pp. 41-42, párr. 56. 
excesivo, a la luz de la regulación actual, dejar que un Estado se vea obligado a soportar tal carga en contra de su voluntad.

Es cierto que la teoría encierra una lectura hacia la cual puede mostrarse cierta comprensión: si un Estado no puede frenar las acciones de grupos terroristas en su territorio que suponen una amenaza para la paz y seguridad internacionales y tampoco nada se hace desde el Consejo de Seguridad, ¿habremos de cruzarnos de brazos y dejar que sigan actuando sin mayores trabas? No parece lo mas sensato, no, pero tampoco debe perderse de vista la prudencia a la hora de reaccionar contra este tipo de conductas. Usar la fuerza debería seguir siendo algo excepcional y argumentos que, como este, caminan por el filo de la navaja, no deberían alimentarse con ligereza. Coincido, pues, con lo que declarara Kevin Jon Heller al cuestionarse si la doctrina del Estado que no quiere o no puede era correcta: quizá lo es, "pero esa postura tiene que ser el final del análisis y no el principio» ${ }^{72}$.

La teoría, ciertamente, no ha recibido aún apoyo suficiente como para que podamos hablar de una tendencia que empieza a ser aceptada por una generalidad de Estados y ni siquiera una amenaza como el terrorismo debería justificarla. Debieran sopesarse tal vez otras alternativas, pero lo que cada vez parece más claro es que el conjunto de normas que regulan el uso de la fuerza y la legítima defensa necesitan una revisión urgente que permita ofrecer a los Estados la posibilidad de respuestas eficaces para garantizar su seguridad.

\section{RESUMEN}

SOBRE LA DOCTRINA «UNWILLING OR UNABLE STATE» (¿PODRÍA EL FIN JUSTIFICAR LOS MEDIOS?)

Se aborda en este artículo la doctrina que propugna la posibilidad de que un Estado emplee la fuerza en el territorio de otro que haya demostrado que no quiere o no puede hacer frente a grupos terroristas que desde allí atacan a otros. Se analiza, en concreto, su contenido, su base jurídica y si, pese a lo peligroso de sus planteamientos, puede hablarse de una tendencia creciente a aceptarla, sobre todo a la luz de su aplicación reciente en la lucha contra el Daesh en Siria. Exponer alternativas que permitirían, en su caso, a los Estados afrontar la amenaza terrorista desde otra perspectiva es otro de los objetivos que estas páginas persiguen.

Palabras clave: uso de la fuerza, legítima defensa, terrorismo, Estado que no quiere o no puede, actores no estatales, Daesh.

\section{ABSTRACT \\ ABOUT THE «UNWILLING OR UNABLE DOCTRINE» (COULD THE END JUSTIFY THE MEANS?)}

This article addresses the doctrine that defends the possibility that the States use the force within the territory of another which is unwilling or unable to face terrorist groups

${ }^{72}$ Heller, K. J., «The unwilling or unable standard for...», op. cit., nota 5. 
using that territory to attack others. In particular, it reflects on this doctrine's contents, legal basis and its application to the fight against ISIS in Syria. It also evaluates the existence of a growing tendency to accept it and defends alternatives which could help to face the terrorist threat.

Keywords: use of force, self defence, terrorism, unable/unwilling State, non-state actors, Daesh. 